\title{
The Role of Calcium in Glucagon Release, Interactions between Glucose and Calcium
}

\author{
V. Leclercq-Meyer, J. Marchand and W. J. Malaisse \\ Laboratory of Experimental Medicine, Université Libre de Bruxelles, Bruxelles, BeIgium
}

\begin{abstract}
Summary. The interrelationships between glucose and calcium in glucagon release were investigated using the dynamic system of the in vitro perfused rat pancreas. When calcium deprivation was induced in the presence of fixed concentrations of glucose prevailing throughout the experiments $(3.3,5.5,8.3$ and $16.6 \mathrm{mM}$ ), an enhancement of glucagon release invariably occurred, the shape and amplitude of such response differing in relation to the environmental glucose concentration. Such enhancement of glucagon release was readily reversible upon restoration of normal calcium levels. By contrast, during the period of calcium deprivation itself, glucagon release was little influenced by either raised (from 3.3 to $16.6 \mathrm{mM}$ ) or decreased (from 16.6 to $3.3 \mathrm{mM}$ ) glucose concentrations. These results clearly indicate that calcium plays, at least, a dual role - both inhibitory and permissive in glucagon secretion, but the intimate mechanisms by which calcium exerts such a dual action are at present unknown.
\end{abstract}

Key words: Glucagon release, insulin release, perfused rat pancreas, calcium, glucose.

The key role of calcium in the release of insulin is well recognized $[9,21,28]$. Such a role of calcium in the secretory process of the A-cell remains a matter of debate. Several investigators have shown that calcium deprivation resulted in an enhancement of glucagon release $[4,6,14,17,34]$; others have observed that calcium deprivation was without effect [22], or reported on the calcium dependency of glucagon secretion [8]. Further discrepancies exist concerning the effect of raised calcium levels, which have been reported not to affect $[2,3,12,14]$, or to inhibit gluca- gon release [23]. Last, divalent cation ionophores, which supposedly transport calcium across biological membranes, have been observed to provoke a stimulation of glucagon release $[1,35]$.

The present investigation was undertaken in an attempt to gain a closer understanding of the role of calcium in glucagon release, using the dynamic system of the in vitro perfused rat pancreas. Two approaches were employed in order to study the relationships between calcium and glucose. In the first, calcium deprivation was induced 40 minutes after the start of the perfusion, in the presence of a fixed concentration of glucose prevailing throughout the experiment (3.3, $5.5,8.3$ and $16.6 \mathrm{mM}$ ). In the second, acute changes in the concentration of glucose (from 3.3 to $16.6 \mathrm{mM}$, or the reverse) were performed either early (10 minutes) or late (40 minutes) during the period of calcium deprivation. The results of these investigations suggest that calcium plays a dual role in the secretory process of the A-cell.

\section{Materials and Methods}

\section{Perfusion System}

The perfusion system has been detailed previously $[13,17,29]$. Fed female albino rats, mean body weight $220 \mathrm{~g}$, were employed in these studies. The pancreases were dissected under Pentobarbital anaesthesia (48 $\mathrm{mg} / \mathrm{kg}$, I. P.), according to the procedure of Loubatières et al. [19], all the adjacent organs, including the duodenum being excluded, thus avoiding the interference of enteric glucagon-like immunoreactivity. They were perfused in situ, and the effluent was collected from the portal vein without recycling. The flow rate was set around $2 \mathrm{ml} /$ minute and the perfusate entered the pancreas at a temperature of $37.5^{\circ} \mathrm{C}$. 


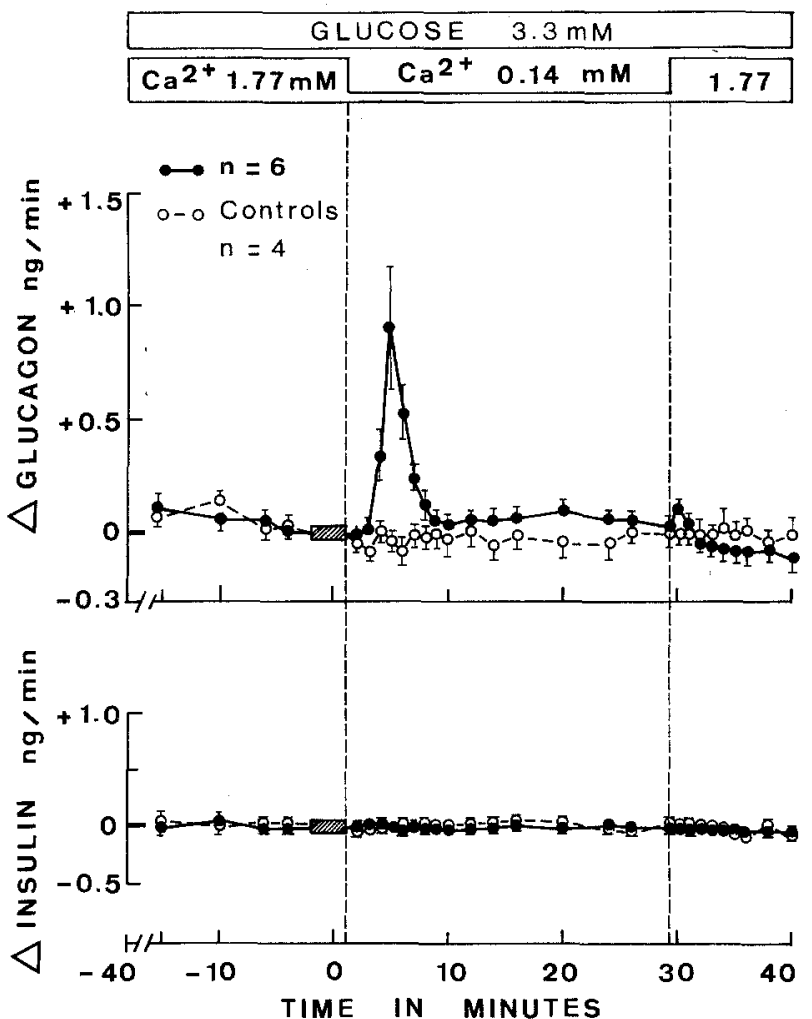

Fig. 1. The effect of calcium deprivation and restoration on glucagon and insulin release form the perfused rat pancreas, in the presence of a $3.3 \mathrm{mM}$ concentration of glucose $(\bullet-\bullet)$. Mean changes in secretion ( \pm SEM) are shown together with the number of individual experiments in each group (n). Control perfusions (O - - O) were performed in the presence of normal calcium levels maintained throughout the experiments: $1.86 \pm 0.02 \mathrm{mM}(\mathrm{n}=4)$. The mean glucagon and insulin output at the end of the control period ( $\min -2$ to $\min +1$, hatched area) averaged $294 \pm 63$ and $113 \pm 9 \mathrm{pg} / \mathrm{min}$, respectively $(\mathrm{n}=10)$

Samples of the effluent were taken at 1 minute intervals in chilled tubes containing $2000 \mathrm{KIU}$ Trasylol (kindly donated by Dr. G. Wald, Bayer, Brussels), and frozen at $-25^{\circ} \mathrm{C}$ until time of assay.

The perfusion medium was a modified Krebs Ringer bicarbonate buffer with the following composition: $\mathrm{NaCl}, 118.5 \mathrm{mM} ; \mathrm{KCl}, 4.7 \mathrm{mM}$; $\mathrm{KH}_{2} \mathrm{PO}_{4}, 1.2 \mathrm{mM} ; \mathrm{MgSO}_{4}, 1.2 \mathrm{mM} ; \mathrm{NaHCO}_{3}, 25$ $\mathrm{mM} ; \mathrm{CaCl}_{2}, 2 \mathrm{mM}$. The medium was equilibrated against a mixture of $\mathrm{O}_{2}$ and $\mathrm{CO}_{2}(95: 5)$ with a resulting $\mathrm{pH}$ of 7.4. In the earlier experiments (Figs. 1 to 5), the buffer was supplemented with bovine albumin $(4 \%, \mathrm{~W} / \mathrm{V}$; fraction V, Pentex, Miles Laboratories, Kankakee, USA). In the more recent experiments (Figs. 6 and 7), the buffer was supplemented with dextran $(4 \%$, W/V; T70, Pharmacia, Uppsala, Sweden) and a small amount of bovine albumin $(0.5 \%$ W/V; fraction V, Sigma Chemical Co., St. Louis, USA). Because we had observed that the responsiveness of the endocrine pancreas differed markedly ac-

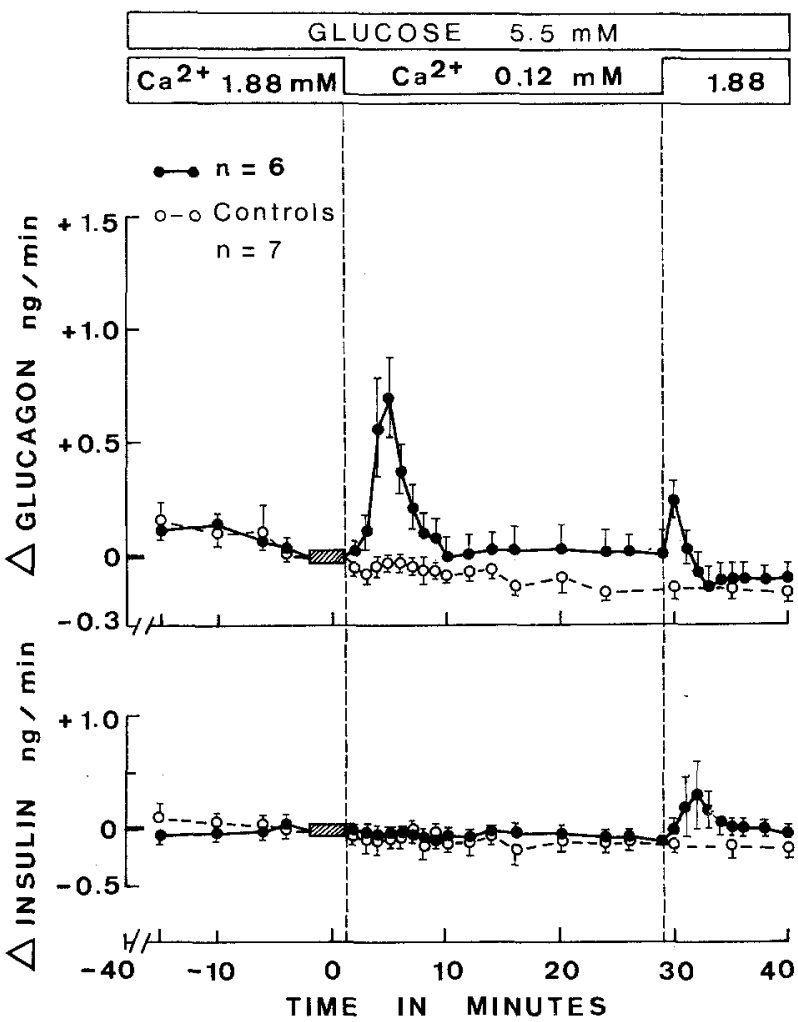

Fig. 2. The effect of calcium deprivation and restoration on glucagon and insulin release from the perfused rat pancreas, in the presence of a $5.5 \mathrm{mM}$ concentration of glucose $(\bullet-\bullet)$. Presentation as in Fig. 1. In the control experiments (O- - O), the calcium concentration was $1.88 \pm 0.05 \mathrm{mM}(\mathrm{n}=4)$. The mean glucagon and insulin output at the end of the control period $(\min -2$ to $\min$ +1 , hatched area) averaged $364 \pm 47$ and $165 \pm 22 \mathrm{pg} / \mathrm{min}$, respectively $(\mathrm{n}=13)$

cording to the colloid composition of the perfusate [13], appropriate control perfusions were run with each type of perfusate.

The secretagogues were administered through a side-arm syringe working at a flow rate of $0.075 \mathrm{ml} /$ minute (Braun infusion pump, Melsungen, Germany). During the control periods, an infusion of the basic medium was maintained at the same speed. In the experiments which included a change in the concentration of calcium, the normal calcium concentration was obtained by the side-arm infusion of $\mathrm{CaCl}_{2}$ dissolved in a perfusate in which $\mathrm{NaHCO}_{3}$ was deleted, in order to avoid precipitation of the calcium salts. Calcium deprivation was induced by stopping this calcium infusion, no calcium having been added to the basic medium.

\section{Analytical Methods}

Glucagon and insulin were estimated on $0.2 \mathrm{ml}$ samples, using a combined radioimmunoassay for these 


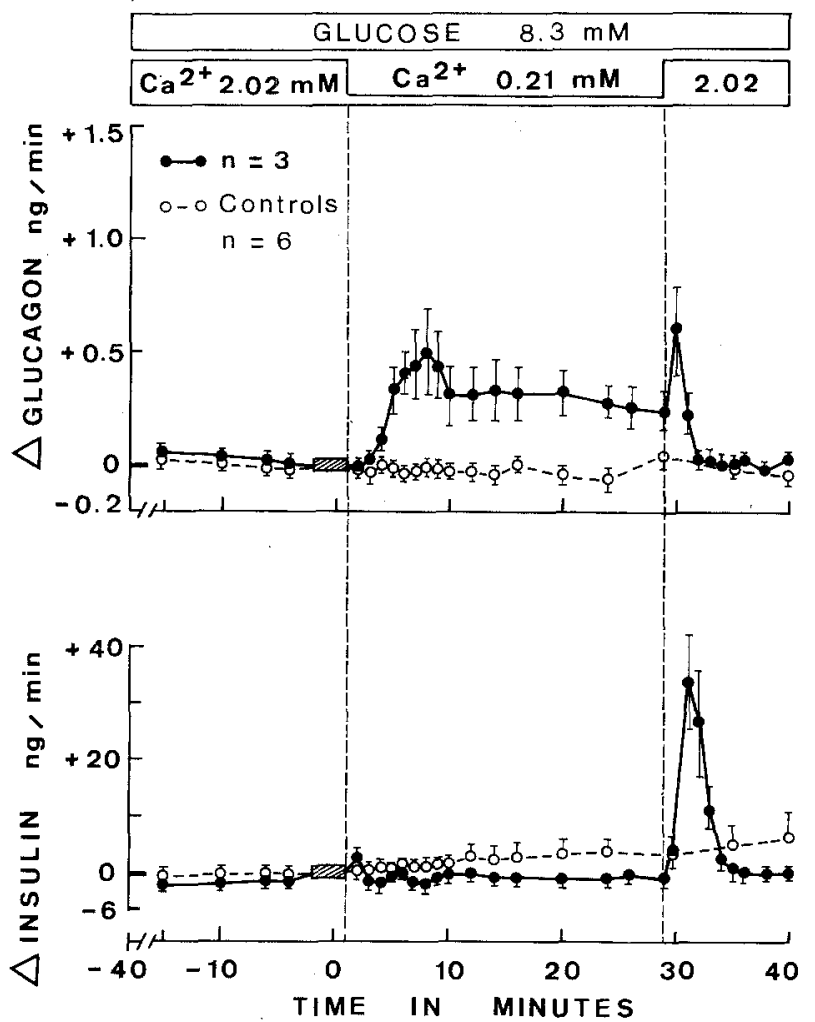

Fig. 3. The effect of calcium deprivation and restoration on glucagon and insulin release from the perfused rat pancreas, in the presence of a $8.3 \mathrm{mM}$ concentration of glucose $(\bullet-\bullet)$. Presentation as in Fig. 1. In the control experiments (O- - $)^{\circ}$, the calcium concentration was $1.72 \pm 0.03 \mathrm{mM}(\mathrm{n}=3)$. The mean glucagon and insulin output at the end of the control period $(\min -2$ to $\min$ +1 , hatched area) averaged $217 \pm 55$ and $5,220 \pm 251 \mathrm{pg} / \mathrm{min}$, respectively $(\mathrm{n}=9)$

hormones [16]. The standards were purified beefpork glucagon (Lot No. 258-234-B-161-1, a gift from Dr. M. A. Root, Eli Lilly Co., Indianapolis, USA) and rat insulin (Lot R170, mean biological activity of 21.4 IU/mg, a gift from Dr. J. Schlichtkrull, Novo, Bagsvaerd, Denmark). Total calcium in the perfusates was kindly determined by Dr. R. Leclercq (I. M. C. Anderlecht, Department of Clinical Biology, chief: Dr. P. Mascart), with the cresolphtalein method using a SMA 12-60 Technicon. Glucose was titrated in the pancreatic effluent by a ferricyanide method using a first generation Technicon analyser.

\section{Calculations and Presentation of Results}

Because secretory rates varied to some extent among individual perfusions, the majority of the results were expressed on the graphs as the difference in hormonal secretion ( $\Delta$ glucagon and $\Delta$ insulin), relative to the mean hormonal output recorded at the end of the equilibration period (Figs. 1 to 5 , between $\min -2$ and $\min +1$, hatched areas). The actual secretory rates corresponding to these hatched areas are reported in the legends of the figures. Statistical analyses were conducted using Student's paired or nonpaired $t$ tests [30].

\section{Results}

\section{The Effects of Calcium Deprivation and Restoration in the Presence of Fixed Concentrations of Glucose}

The results of these experiments are illustrated in Figs. 1 to 3 , and in Fig. 2 of a previous publication [17]. In the presence of the lowest $(3.3 \mathrm{mM})$ glucose concentration, a sharp and elevated early peak in glucagon secretion was observed (Fig. 1, upper panel). This early glucagon response to calcium deprivation progressively decreased in amplitude at the higher glucose levels (Figs. 2 and 3, upper panels). By contrast, the secretory rates observed during the late phase progressively increased in the presence of higher glucose levels (Figs. 1 to 3, upper panels). Total glucagon output during the late phase (min 10 to 29) was significantly higher $(\mathrm{P}<0.05)$ at low than at normal calcium concentration, both at glucose 8.3 (Fig. 3 ) and $16.6 \mathrm{mM}$ (see Fig. 2 in ref. 17).

The stimulation of glucagon release provoked by calcium depletion was, at all concentrations of glucose, totally reversed upon restoration of normal calcium levels (Figs. 1 to 3, and Fig. 2 in ref. 17). Such a return towards control secretory rates was invariably preceded by a short-lived "off-response".

Insulin release followed the patterns expected from the current knowledge on the requirement of calcium in the secretory process of the B-cell $[9,21$, $28]$. Thus, at the lower ( 3.3 and $5.5 \mathrm{mM}$ ) concentrations of glucose, the removal or restoration of calcium had no, or only a small, influence on insulin release (Figs. 1 and 2, lower panels). In the presence of the higher (8.3 and $16.6 \mathrm{mM}$ ) glucose concentrations, calcium deprivation provoked a definite inhibition of insulin release, followed by a strong outburst of insulin upon calcium restoration (Fig. 3, and Fig. 2 in ref. 17).

\section{The Effects of Acute Changes in the Concentration of Glucose Performed Early (10 minutes) during the Period of Calcium Deprivation}

In the first set of experiments the perfusion was started in the presence of a $3.3 \mathrm{mM}$ concentration of glucose (Fig. 4). The reduction in the concentration of calcium 40 minutes after the start of the perfusion provoked the expected early sharp peak of glucagon release. When, 10 minutes later, the glucose concentration was increased from 3.3 to $16.6 \mathrm{mM}$, no obvious change in the rate of glucagon secretion could be 


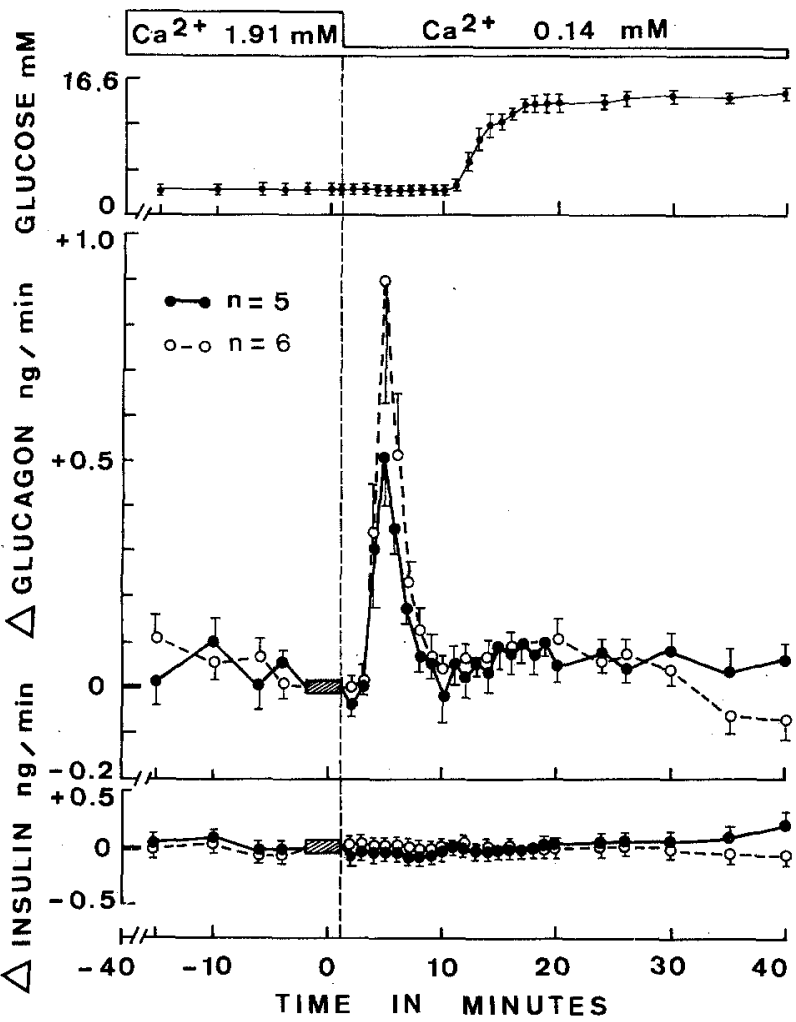

Fig. 4. The effect of an increase from 3.3 to $16.6 \mathrm{mM}$ in the concentration of glucose, applied early $(10 \mathrm{~min})$ during the period of calcium deprivation, on the release of glucagon and insulin from the

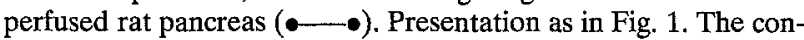
trol perfusions only included a change in the concentration of calcium $\left(0-0_{0}\right.$ ). The mean glucagon and insulin output at the end of the control period ( $\min -2$ to $\min +1$, hatched area) averaged $252 \pm 61$ and $153 \pm 32 \mathrm{pg} / \mathrm{min}$, respectively $(\mathrm{n}=11)$

detected (Fig. 4, upper panel, closed circles and solid lines). Thus, the glucagon secretory rates were, at no time, statistically different (non-paired $t$ test) from those which were obtained in the appropriate control experiments exposed to the sole stimulus of calcium deprivation (Fig. 4, upper panel, open circles and dotted lines). Insulin release was low in the presence of the $3.3 \mathrm{mM}$, non-stimulatory, concentration of glucose and remained unaffected by either the decrease in the concentration of calcium or the subsequent increase in the concentration of glucose (Fig. 4, lower panel).

In the second set of experiments the perfusion was started in the presence of a $16.6 \mathrm{mM}$ concentration of glucose, which was thereafter decreased to $3.3 \mathrm{mM}$ (Fig. 5). Such a decrease induced a slight inhibition of the secretory response of the A-cell to calcium deprivation (Fig. 5, upper panel, closed circles and solid lines). By paired comparison with the glucagon output observed between 10 and 12 minutes (before the low-

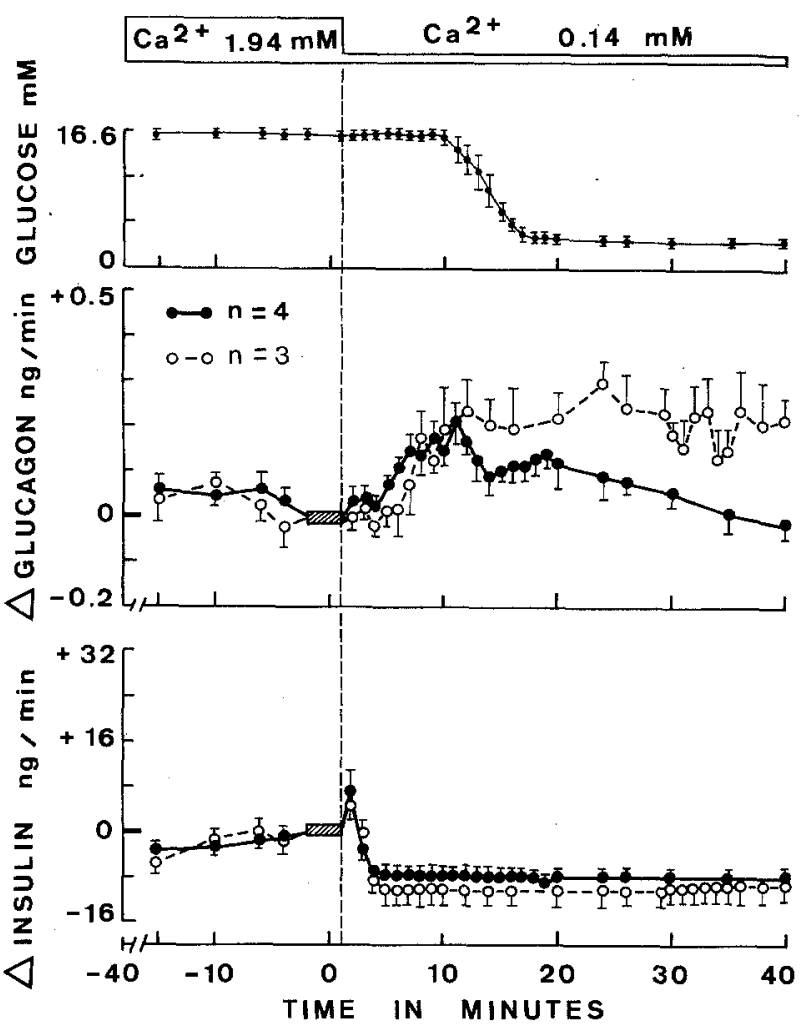

Fig. 5. The effect of a decrease from 16.6 to $3.3 \mathrm{mM}$ in the concentration of glucose, applied early $(10 \mathrm{~min})$ during the period of calcium deprivation, on the release of glucagon and insulin from the perfused rat pancreas (-•). Presentation as in Fig. 1. The control perfusions only included a change in the concentration of calcium $\left(0-0_{-}\right)$. The mean glucagon and insulin output at the end of the control period ( $\min -2$ to $\min +1$, hatched area) averaged $238 \pm 71$ and $8,794 \pm 1,360 \mathrm{pg} / \mathrm{min}$, respectively $(n=7)$

ering of glucose), the inhibition was significant for the period 14 to 16 minutes $(\mathrm{p}<0.02)$. By non-paired comparison, the secretory rates observed from 24 to 40 minutes were significantly lower $(p<0.05)$ than those obtained in the experiments submitted to the sole stimulus of calcium deprivation (Fig. 5, upper panel, open circles and dotted lines). The decrease in the concentration of glucose did not further modify the rate of insulin release already inhibited upon calcium deprivation (Fig. 5, lower panel).

\section{The Effects of Acute Changes in the Concentration of Glucose Performed Late (40 minutes) during the Period of Calcium Deprivation}

These experiments were performed throughout using a perfusate to which no $\mathrm{CaCl}_{2}$ had been added.

In the first set of experiments, the perfusions were started in the presence of a low $(3.3 \mathrm{mM})$ concentration of glucose (Fig. 6). During the equilibration period, the output of glucagon was comparably high, 

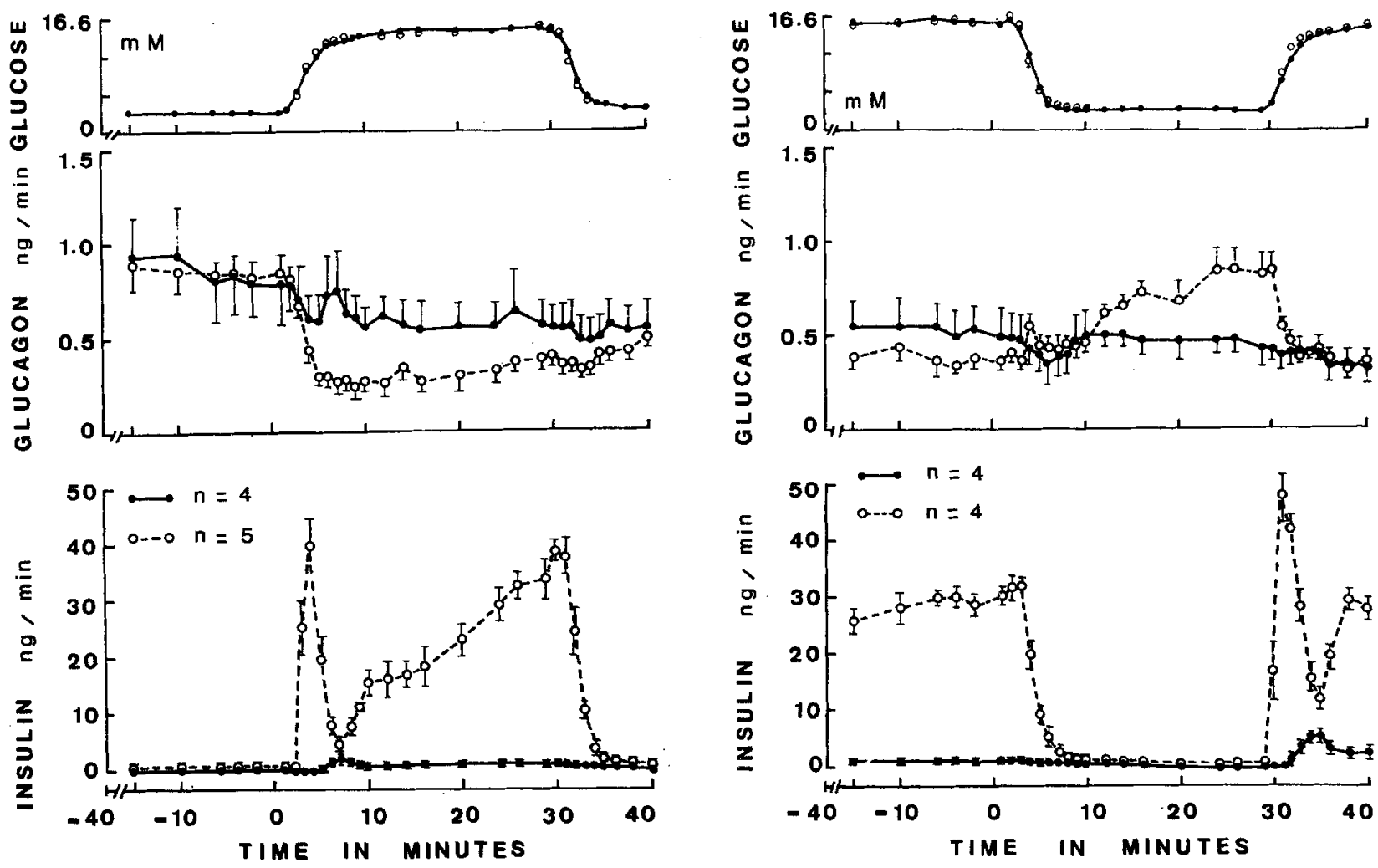

Fig. 6. The effect of a rise from 3.3 to $16.6 \mathrm{mM}$ in the concentration of glucose, applied late $(40 \mathrm{~min})$ during the period of calcium deprivation, on the release of glucagon and insulin from the perfused rat pancreas $(\bullet-\bullet)$. The mean secretory rates $( \pm$ SEM) are indicated together with the number of individual experiments in each group (n). The calcium concentration was $0.09 \pm 0.01 \mathrm{mM}$ $(n=4)$. In the control experiments the calcium concentration amounted to $1.94 \pm 0.04(\mathrm{n}=5)$

whether the perfusions were performed in the absence of calcium or at normal calcium levels. Increasing the concentration of glucose after 40 minutes of calcium deprivation produced a small and short-lasting inhibition of glucagon release. By paired comparison with the output of glucagon recorded between -2 and +1 minutes, such inhibition was significant at $4(\mathrm{p}<0.05)$ and $5(\mathrm{p}<0.05)$ minutes, but was far from resembling the pronounced inhibition evoked by glucose in the control experiments, performed at normal calcium levels (Fig. 6, upper panel, open circles and dotted lines; $\mathrm{p}<0.01$ starting at +3 minutes). At low calcium concentration, the restoration of a low glucose concentration towards the end of the experiment was again followed by a slight inhibition of glucagon release (Fig. 6, upper panel; $\mathrm{p}<0.01$ for 33 to 35 minutes) by paired comparison with the output between 29 and 30 minutes). At normal $\mathrm{Ca}^{2+}$ level, the restoration of the low glucose concentration failed to cause any obvious immediate changes in glucagon release.

Fig. 7. The effect of a decrease from 16.6 to $3.3 \mathrm{mM}$ in the concentration of glucose, applicd late ( $40 \mathrm{~min})$ during the period of calcium deprivation, on the release of glucagon and insulin from the perfused rat pancreas $(\bullet-)$. Presentation as in Fig. 6 . The calcium concentration was $0.09 \pm 0.01(n=4)$. In the control experiments the calcium concentration amounted to $1.93 \pm 0.03(\mathrm{n}=4)$

During the equilibration period, in the presence of the $3.3 \mathrm{mM}$, non-stimulatory, concentration of glucose, the release of insulin was low, whether in the presence or absence of calcium (Fig. 6, lower panel). Upon the subsequent rise in the concentration of glucose, a delayed (5 to 6 minutes) and small increase in insulin release was detectable, reaching a maximum of $2,240 \mathrm{pg} /$ minute at the $7 \mathrm{th}$ minute and thereafter stabilizing at a mean value of $1,299 \mathrm{pg} /$ minute. Such response was negligible when compared to that seen in the presence of normal calcium levels (Fig. 6, lower panel, open circles and dotted lines), but it nevertheless represented a tenfold increase in output rate over that seen during the equilibration period at $3.3 \mathrm{mM}$ glucose ( $84 \pm 13 \mathrm{pg} /$ minute).

In the second set of experiments, the perfusions were started in the presence of a high $(16.6 \mathrm{mM})$ concentration of glucose (Fig. 7). The output of glucagon during the equilibration period was higher using the calcium-depleted perfusates than in the presence of normal calcium levels (Fig. 7, upper panel), but the 
difference, was not significant. The subsequent decrease in the concentration of glucose was accompanied by a slight and short-lived inhibition of glucagon release, which was significant by paired comparison with the output rates recorded between -2 and +1 minutes (Fig. 7, upper panel, +6 and +8 minutes: $p<0.01 ;+7$ minutes: $p<0.05)$. Thereafter, the rate of glucagon release resumed initial values. The foregoing behaviour of the A-cell was clearly in contrast with that seen in the experiments performed in the presence of normal calcium levels, in which the decrease in the concentration of glucose induced at first a small peak of secretion, followed by a progressive increase in glucagon release until the 30 th minute (Fig. 7, upper panel, open circles and dotted lines; minutes $+4: p<0.001 ;+6: p<0.05 ;+12$ to +30 : $\mathrm{p}<0.01$ by paired comparison with the output rates between -2 and +1 minutes). Insulin release was, as expected, strongly inhibited using the calcium-deprived perfusates (Fig. 7, lower panel). Nevertheless, as previously noted for the experiments illustrated in Fig.6, the rate of insulin release was significantly higher in the presence of 16.6 than in that of $3.3 \mathrm{mM}$ glucose, amounting to $1,212 \pm 221 \mathrm{pg} /$ minute during the equilibration period, i.e. again a 10 times higher output rate than that of $75 \mathrm{pg} /$ minute estimated near +30 minutes. Moreover, the increase in the concentration of glucose towards the end of the experiment induced an even higher, although delayed, response from the B-cell, the output rate reaching a maximum of $5,255 \mathrm{pg} /$ minute at 34 minutes, and thereafter stabilizing around $2,341 \mathrm{pg} /$ minute.

\section{Discussion}

\section{Effect of Glucose upon Glucagon Release at Normal Calcium Concentration}

In the presence of normal calcium levels, glucagon release was increased at low and inhibited at high glucose concentration (Figs. 6 and 7), in good agreement with the classical negative feedback between glucose and glucagon secretion [31]. The glucose-induced inhibition of glucagon release was a rapid and abrupt phenomenon. By contrast, the reversibility of such a process upon lowering of glucose concentration occurred in a more progressive manner. Such delayed reversibility has been noted previously $[7,16,26,29$, 33].

\section{Effect of Glucose upon Glucagon Release at Low Calcium Concentration}

In the presence of a low calcium concentration, the A-cell was only little influenced by raised or decreased glucose concentrations. This was noted after an extended (40 minutes, Figs. 6 and 7 ) as well as a short period of calcium deprivation (10 minutes, Figs. 4 and $5)$. The variations of glucagon release were indeed always slight, and even of doubtful significance towards the end of the experiments. Curiously, the decrease in glucose concentration was now also accompanied by a small decrease in glucagon release (Figs. 5 and 7). Thus, in the presence of low calcium levels, the A-cell not only displays a reduced sensitivity to glucose, but also seems to lose its positive response to decreased glucose concentrations.

\section{The Dual Role of Calcium in Glucagon Secretion}

The foregoing results suggest that calcium plays a permissive role in allowing glucose to exert its normal effect upon glucagon release. Such a situation is reminiscent of that seen when arginine is used as the glucagonotropic factor [8]. On the other hand, calcium also plays an inhibitory role in the A-cell. This is indicated by the enhancement of glucagon release which is observed upon calcium deprivation (Figs. 1 to 5) $[4,6,14,17,34]$. It further is supported by the fact that such an enhancement is immediately and totally reversed upon restoration of normal calcium levels at all glucose concentrations studied (Figs. 1 to 3) [17], and the report of the inhibitory effect of calcium on glucagon release in the dog [23].

How calcium might exert its dual role on glucagon secretion is at present unknown. The permissive effect of calcium apparently supports the previous suggestion that glucagon secretion, [8] like that of insulin [9, $21,28]$, is a calcium-dependent process. However, it should be stressed that, in contrast to insulin, glucagon secretion is not inhibited by external calcium lack. Thus, even during prolonged calcium deprivation ( 40 minutes), the rates of glucagon release never fell below the values found at normal calcium concentration, although they ultimately levelled off at nearly the same rates as those seen in control experiments performed at the same glucose level (Figs. 1 to 3,6 and 7) [17]. This would suggest that the A-cell kept the memory or was still somehow informed of the actual glucose concentration, despite the absence of extracellular calcium.

Based on present knowledge on A-cell function, a few working hypotheses might be outlined concerning the possible mechanisms by which calcium exerts its dual effects on glucagon secretion, resulting in the observed complex relationships with glucose. These could include an interaction at the membrane level, calcium deprivation possibly altering the biophysical properties and stability of the membrane and of its yet hypothetical glucose receptor [27], or modifying the 
electrical, structural and functional coupling between adjacent A- and B-cells [25], as already documented in other tissues [18] and by time-lapse cinematography of monolayer cultures of pancreatic endocrine cells [24]. Secondly, calcium might interact with the metabolism of glucose $[5,20]$ and the cAMP system in the A-cell $[10,11]$. In this line of thought, it seems most interesting that the effect of cAMP seems modulated by the extracellular calcium concentration, the nucleotide stimulating at low and inhibiting glucagon release at high calcium concentration [34]. Third, calcium might interact with the microtubular-microfilamentous system $[6,15]$, which has been postulated to be responsible for the migration and extrusion of secretory granules in a calcium-dependent manner in the B-cell [32]. Last, there remains the possibility that calcium and glucose might alter the secretion of hormones (insulin, somatostatin) from adjacent islet cells, these hormones possibly in turn influencing glucagon release.

The mere enumeration of these various hypotheses clearly reflects our ignorance as to the intimate role of calcium in glucagon release. Any model dealing with this problem should be able to account for the dual role of calcium upon the secretory response of the A-cell, as revealed by the present work. In addition, a stimulatory effect of calcium might have to be integrated in such a model, in view of the stimulatory effect of calcium ionophores on glucagon release [1, 35].

Acknowledgements. This work was supported in part by grants 3.4527 .75 and 3.4537 .76 from the FRSM (Belgium). The authors wish to thank Mrs. B. Noël for skilled secretarial help.

\section{References}

1. Ashby, J. P., Speake, R. N.: Insulin and glucagon secretion from isolated islets of Langerhans. The effects of calcium ionophores. Biochem. J. 150, 89-96 (1975)

2. Bhatena, S., Perrino, P., Voyles, N., Smith, S., Wilkins, S., Coy, D. H., Schally, A., Recant, L.: Reversal of somatostatin inhibition of insulin and glucagon secretion. Diabetes 24 (Suppl. 2), 408 (1975)

3. Böttger, I., Faloona, G. R., Unger, R. H.: The effect of calcium and other salts upon the release of glucagon-like immunoreactivity (GLI) from the gut. J. clin. Invest. 51, 831-836 (1972)

4. Edwards, J. C.: A-cell metabolism and glucagon secretion. Postgrad. med. J. 49 (August Suppl.), 611-615 (1973)

5. Edwards, J. C., Hellerström, C., Petersson, B., Taylor, K. W.: Oxidation of glucose and fatty acids in normal and in $\mathrm{A}_{2}$-cell rich pancreatic islets from guinea-pigs. Diabetologia $8,93-98$ (1972)

6. Edwards, J. C., Howell, S. L.: Effects of vinblastine and colchicine on the secretion of glucagon from isolated guinea-pig islets of Langerhans. FEBS Letters 30, 89-92 (1973)
7. Frankel, B. J., Gerich, J. E., Hagura, R., Fanska, R. E., Gerritsen, G. C., Grodsky, G. M.: Abnormal secretion of insulin and glucagon by the in vitro perfused pancreas of the genetically diabetic chinese hamster. J. clin. Invest. 53, 1637-1646 (1974)

8. Gerich, J. E., Frankel, B. J., Fanska, R., West, L., Forsham, P. H., Grodsky, G. M.: Calcium dependency of glucagon secretion from the in vitro perfused rat pancreas. Endocrinology 94, 1381-1385 (1974)

9. Grodsky, G. M.: A threshold distribution hypothesis for packet storage of insulin. II. Effect of calcium. Diabetes 21 (Suppl. 2), 584-593 (1972)

10. Howell, S. L., Whitfield, M.: Cytochemical localization of adenylate cyclase activity in rat islets of Langerhans. J. Histochem. Cytochem. 20, 873-879 (1972)

11. Howell, S. L., Edwards, J. C., Montague, W.: Regulation of adenylate cyclase and cyclic-AMP protein kinase activities in $\mathrm{A}_{2}$-cell rich guinea-pig islets of Langerhans. Horm. Metab. Res. 6, 49-52 (1974)

12. Kuzuya, T., Kajinuma, H., Ide, T.: Effect of intrapancreatic injection of potassium and calcium on insulin and glucagon secretion in dogs. Diabetes 23, 55-60 (1974)

13. Leclercq-Meyer, V., Marchand, J., Leclercq, R., Malaisse, W. J.: Glucagon and insulin release by the in vitro perfused rat pancreas. Influence of the colloid composition of the perfusate. Diabète Métab. 2, 57-65 (1976)

14. Leclercq-Meyer, V., Marchand, J., Malaisse, W. J.: The effect of calcium and magnesium on glucagon secretion. Endocrinology 93, 1360-1370 (1973)

15. Leclercq-Meyer, V., Marchand, J., Malaisse, W. J.: Possible role of a microtubular-microfilamentous system in glucagon secretion. Diabetologia 10, 215-224 (1974)

16. Leclercq-Meyer, V., Marchand, J., Rebolledo, O., Malaisse, W. J., Leclercq, R.: A combined radioimmunoassay for glucagon and insulin. Diabetologia 11, 419-425 (1975)

17. Leclercq-Meyer, V., Rebolledo, O., Marchand, J., Malaisse, W. J.: Glucagon release: Paradoxical stimulation by glucose during calcium deprivation. Science 189, 897-899 (1975)

18. Loewenstein, W. R.: Permeability of membrane junctions. Ann. N.Y. Acad. Sci. 137, 441-472 (1966)

19. Loubatières, A., Mariani, M. M., Ribes, G., de Malbosc, G., Chapal, J.: Etude expérimentale d'un nouveau sulfamide hypoglycémiant particulièrement actif, le HB 419 ou glibenclamide. I. Action betacytotrope et insulino-sécrétrice. Diabetologia 5, 1-10 (1969)

20. Lundqvist, G.: Enzymatic studies of glucose phosphorylation in the glucagon producing cells of the duck pancreas. Horm. Metab. Res. 4, 83-86 (1972)

21. Malaisse, W. J.: Hormonal and environmental modification of islet activity. In: Handbook of physiology. Section 7: Endocrinology 1: Endocrine Pancreas (eds. N. Freinkel, D. F. Steiner), pp. 237-260. Washington, D. C.: American Physiological Society 1972

22. Nonaka, K., Sugase, T., Foa, P. P.: Glucagon release by the isolated pancreatic islets of the Syrian Hamster. In: Proceedings of the Seventh Congress of the International Diabetes Federation (eds. R. R. Rodriguez, J. Vallance-Owen), Excerpta med. Intern. Congr. Ser. (Amst.) 231, 625-635 (1971)

23. Ohneda, A., Matsuda, K., Horigome, K., Ishii, S., Yamagata, S.: Effect of intrapancreatic administration of calcium upon glucagon secretion in dogs. Tohoku J. exp. Med. 113, 301-311 (1974)

24. Orci, L., Blondel, B., Malaisse-Lagae, F., Ravazzola, M., Wollheim, C., Malaisse, W. J., Renold, A. E.: Cell motility and insulin release in monolayer cultures of endocrine pancreas. Diabetologia 10, 382 (1974)

25. Orci, L., Malaisse-Lagae, F., Ravazzola, M., Rouiller, D., Renold, A. E., Perrelet, A., Unger, R. H.: A morphologic basis for 
intercellular communication between $\alpha$ - and $\beta$-cells in the endocrine pancreas. J. clin. Invest. 56, 1066-1070 (1975)

26. Pagliara, A. S., Stillings, S. N., Haymond, M. W., Hover, B. H., Matschinsky, F. M.: Insulin and glucose as modulators of the amino acid-induced glucagon release in the isolated pancreas of alloxan and streptozotocin diabetic rats. J. clin. Invest. 55, 244-255 (1975)

27. Pagliara, A. S., Stillings, S. N., Hover, B., Martin, D. M., Matschinsky, F. M.: Glucose modulation of amino acid-induced glucagon and insulin release in the isolated perfused rat pancreas. J. clin. Invest. 54, 819-832 (1974)

28. Randle, P. J., Hales, C. N.: Insulin release mechanisms. In: Handbook of Physiology. Section 7: Endocrinology 1: Endocrine Pancreas (eds. N. Freinkel, D. F. Steiner), pp. 219-235. Washington, D. C.: American Physiological Society 1972

29. Rebolledo, O., Leclercq-Meyer, V., Marchand, J., Leclercq, R., Malaisse, W. J.: Failure of parathormone to affect insulin and glucagon release from the perfused rat pancreas. Horm. Metab. Res. 7, 287-290 (1975)

30. Snedecor, G. W.: Statistical methods. Ames: Iowa State University Press 1956

31. Unger, R. H., Lefebvre, P. J.: Glucagon physiology. In: Glucagon, molecular physiology, clinical and therapeutic implications (eds. P. J. Lefebvre, R. H. Unger), pp. 213-244. Oxford: Pergamon Press 1972
32. Van Obberghen, E., Somers, G., Devis, G., Ravazzola, M., Malaisse-Lagae, F., Orci, L., Malaisse, W. J.: Dynamics of insulin release and microtubular-microfilamentous system. VII. Do microfilaments provide the motive force for the translocation and extrusion of beta granules? Diabetes 24, 892-901 (1975)

33. Weir, G. C., Knowlton, S. D., Martin, D. B.: Glucagon secretion from the perfused rat pancreas. Studies with glucose and catecholamines. J, clin. Invest. 54, 1403-1412 (1974)

34. Wollheim, C. B., Blondel, B., Müller, W. A., Sharp, G. W. G.: Relation of $\mathrm{Ca}^{++}$to cyclic AMP induced alterations of glucagon release in pancreatic monolayer cultures. Europ. J. clin. Invest. 5, 58P (1975)

35. Wollheim, C., Blondel, B., Sharp, G. W. G.: Insulin and glucagon release in pancreatic monolayer cultures: Effect of calcium and ionophore A23187. Diabetologia 10, 391 (1974)

Received: March 15, 1976, and in revised form: July 8, 1976

\section{Dr. V. Leclercq-Meyer}

Laboratoire de Médecine Expérimentale

Boulevard de Waterloo 115

B-1000 Brussels

Belgium

Responsible for the text: Prof. Dr. W. Creutzfeldt, Med. Universitätsklinik, Humboldtallee 1, D-34 Göttingen Prof. Dr. K. Schöffling, Zentrum der Inneren Medizin, Theodor-Stern-Kai 7, D-6 Frankfurt 70 